\title{
The Protection of People with Autism in the Framework of the Council of Europe and the European Union
}

\author{
Giuseppe Palmisano
}

\section{The Protection of People with Autism Within the Wider Framework of International and European Rules on the Rights of Persons with Disabilities}

At the level of the European institutions and supranational organizationsnamely, the Council of Europe and the European Union-ad hoc legal rules or hard law instruments specifically aimed at affirming and protecting the rights of people with autism, imposing on States obligations to respect, protect and promote such rights, in particular in the field of education and employment, do not currently exist.

The special situation and needs of people with autism find rather legal recognition and protection within the wider framework of the rules and legal instruments concerning the rights of persons with disabilities, as well as within the scope of application of the general principle of equality and non-discrimination.

Considering such a wider framework, the most important and comprehensive legal instrument to be taken as a point of reference is, of course, the 2006 United Nations Convention on the Rights of Persons with Disability (CRPD). This Convention elaborates in detail the rights of persons with disabilities and sets out a code of implementation. States parties to the Convention have indeed engaged themselves to develop and carry out policies, laws and administrative measures for securing such rights and abolish laws, regulations, customs and practices that constitute discrimination against persons with disabilities. In addition, the CRPD provides for a monitoring mechanism aimed at assessing the implementation by States of the obligations arising from the Convention in their respective domestic

G. Palmisano $(\bowtie)$

ISGI-CNR, Rome, Italy

Institute for International Legal Studies, National Research Council (CNR), Rome, Italy e-mail: giuseppe.palmisano@cnr.it 
legal orders and practices. But, above all, the Convention sets up all the rights and guarantees referred to persons with disabilities according to a 'social', inclusive approach to disability, and not a medical and 'assistential' approach. In other words, the approach of the CRPD is convincingly based on the awareness that 'disability results from the interaction between persons with impairments and attitudinal and environmental barriers that hinders their full and effective participation in society on an equal basis with others' (Preamble to the Convention). ${ }^{1}$

With regard to the education and employment, the relevant provisions of the CRPD are Article 24 and Article 27, respectively. They are indeed impressively accurate and detailed provisions, at least if compared to the usual wording of other human rights treaty provisions concerning education or employment.

It is worth noting that the CRPD is not only a 'universal' convention; it has also the value of a European legal instrument. In fact, not only the very large majority of European States have ratified the Convention, ${ }^{2}$ but since December 2010 the European Union as such is a party to it. This means that the Convention can be considered and treated as forming part of the law of the Union, which is obviously not without consequences also from the point of view of the domestic law of EU Member States.

But moving to the very specific European regional level, the protection of the rights of persons with disabilities is provided for by two important human rights instruments: the European Social Charter and the Charter of Fundamental Rights of the European Union.

The European Social Charter (ESC) is a legally binding treaty for the protection of social rights, which is embedded in the institutional framework of the Council of Europe. ${ }^{3}$ Article 15 of the Revised Social Charter is expressly devoted to 'the right of persons with disabilities to independence, social integration and participation in the life of the community'.

\footnotetext{
${ }^{1}$ On the CRPD see, inter alias, Arnardóttir and Quinn (2009), Marchisio et al. (2010), and Schulze (2010).

${ }^{2}$ A part from Finland, Ireland and the Netherlands, all other member States of the European Union have ratified the Convention.

${ }^{3}$ The European Social Charter has been signed in Turin more than 50 years ago, in 1961, but it has progressively changed by virtue of a process of institutional reform started in the late 1980s and continued during the 1990s of the last century. This process took the form of three Protocols, adopted in 1988, 1991 and 1995, and the Revised Social Charter, in 1996. In 1988 came the first additional Protocol which added new rights. In 1991, it was adopted the Amending Protocol improving the supervisory mechanism; and in 1995 another additional Protocol, providing for a system of collective complaints, was adopted. The culmination of this reform process came in 1996 with the adoption of the Revised Charter, which added a number of new rights, while at the same time incorporating the basic content of the 1961 Charter and its Protocols. To date, 43 out of the 47 member States of the Council of Europe have ratified either the 1961 Charter or the Revised Charter. 10 States have ratified only the 1961 European Social Charter, and 33 States are parties to the Revised Charter. The countries that have not yet ratified the Charter at all are Liechtenstein, Monaco, San Marino and Switzerland.
} 
The Charter of Fundamental Rights of the European Union (CFREU) has been adopted within the framework of the European Union and, according to Article 6 (1) of the Treaty of Lisbon, has-since 2009-the same legal value as the EU Treaties. Under the Chapter of the Charter devoted to 'Equality', there is a provision-Article 26-concerning specifically the issue of 'Integration of persons with disabilities', and Article 21, on 'Non-discrimination', expressly includes disability among the prohibited grounds of discrimination.

Both the ESC and the CFREU are hard law instruments, and both recognize the rights of persons with disabilities in the fields of education and employment, and the correspondent obligation for European States to protect and ensure such rights. In particular, Article 15(1) and (2) of the Revised European Social Charter states:

\begin{abstract}
With a view to ensuring to persons with disabilities, irrespective of age and the nature and origin of their disabilities, the effective exercise of the right to independence, social integration and participation in the life of the community, the Parties undertake: 1. to take the necessary measures to provide persons with disabilities with guidance, education and vocational training in the framework of general schemes wherever possible or, where this is not possible, through specialised bodies, public or private; 2 . to promote their access to employment through all measures tending to encourage employers to hire and keep in employment persons with disabilities in the ordinary working environment and to adjust the working conditions to the needs of the disabled or, where this is not possible by reason of the disability, by arranging for or creating sheltered employment according to the level of disability. In certain cases, such measures may require recourse to specialised placement and support services. ${ }^{4}$
\end{abstract}

The CFREU is much less detailed and demanding. According to Article 26: 'The Union recognises and respects the right of persons with disabilities to benefit from measures designed to ensure their independence, social and occupational integration and participation in the life of the community'.

\title{
2 International and European Soft Law Instruments Concerning the Protection of People with Autism
}

In addition to these hard law instruments and provisions concerning, in general, the rights of people with disabilities (including persons with autism), there are also-at the international and European level—some soft law instruments dealing with the specific issue of the rights of people with autism. In particular, declarations of principles and resolutions adopted by European or international organizations which do not have legally binding force, but nonetheless have a normative tone.

Starting from the international-universal level, it is worth mentioning the Resolution 67/82 adopted by the UN General Assembly on 12 December 2012, on 'Addressing the socioeconomic needs of individuals, families and societies

\footnotetext{
${ }^{4}$ On Article 15 of the European Social Charter see Palmisano (2013), pp. 337-361.

${ }^{5}$ On Article 26 of the CFREU see O'Brien (2014), pp. 709-748.
} 
affected by autism spectrum disorders, developmental disorders and associated disabilities'. This Resolution, which recalls inter alia some preceding resolutions adopted by the World Health Organization and the so-called 'Dhaka Declaration on Autism Spectrum Disorders and Developmental Disabilities' (adopted by civil society organizations from South-Asia and South-East Asia, on 25 July 2011), significantly calls upon UN Members States: 'to enhance access to appropriate support services and equal opportunities for inclusion and participation in society, by providing, as appropriate, training to public administrators, service providers, carers, caregivers, families and non-professionals on the needs and rights of persons with autism spectrum disorders' (para 1); and 'to ensure inclusive education system at all levels and lifelong learning, as well as to promote vocational training and skills development programmes for persons with autism' (para 5).

But also some Resolutions adopted in the framework of the WHO are relevant, in particular the very recent Resolution WHA67.8 of 24 May 2014, in which the World Health Assembly has urged States 'to develop or update and implement relevant policies, legislation, and multisectoral plans, supported by sufficient human, financial and technical resources to address issues related to ASD and other developmental disorders, as part of a comprehensive approach to supporting all persons living with mental health issues or disabilities'.

At the European level, the first and most wide-ranging soft law document on the protection of people with autism is the 'Charter for persons with autism', which was originally drafted and presented by Autism-Europe more than 20 years ago, in 1992, and which has been adopted by the European Parliament on May 1996.

This Charter points out, first of all, the guiding principle of best interests of the person with autism, along the lines and model of the principle of best interest of the child, established by the 1989 UN Convention on the Rights of the Child. And then it lists a number of rights, concerning all fields of life. The provisions stating such rights are remarkably worded, in a way that the peculiar needs of persons with autism are taken into an appropriate account. Considering the thematic area of education and employment, I wish just to recall, as examples, points 3, 6 and 10 of the Charter, that is: ' 3 . The right of people with autism to accessible and appropriate education'; ' 6 . The right to the equipment, assistance and support services necessary to live a fully productive life with dignity and independence'; ' 10 . The right to meaningful employment and vocational training without discrimination or stereotype'.

In the framework of the Council of Europe, some resolutions and recommendations adopted by the Committee of Ministers should be stressed. In particular, the Resolution of 12 December 2007 and the Recommendation of 21 October 2009, both 'on the education and social inclusion of children and young people with autism spectrum disorders'. It is worth noting that such acts have been prepared by an ad hoc committee- 'the Committee of Experts on the Education and Integration of Children with Autism' - which was established on 2004, in the aftermath of a 
Decision of the European Committee of Social Rights concerning the violation in France of the rights of people with autism. ${ }^{6}$

The Committee of Experts was charged with exchanging information on the definition of autism and related statistics, examining the services provided to children with autism, particularly within the education system, sharing information on experience in the implementation at national level of a coherent policy for this particular group, drawing up recommendations to governments to further education and integration of children with autism. The Committee submitted a substantial report, drafted by Professor Rita Jordan from Birmingham University.

Some points of the Resolutions of the Committee of Ministers of the Council of Europe deserve indeed to be highlighted.

First of all, they affirm the principle that people with ASD have the right to be guaranteed full enjoyment of all human rights and fundamental freedoms, and that failure to promote the rights of people with autism and to ensure equality of opportunities is a violation of their human dignity. From this perspective, Governments are called upon to encourage education and social inclusion of children and young people with autism, by involving non-governmental organisations representing children and young people with ASD and their families in the implementation and monitoring of the measures adopted to that effect.

And then the Resolutions list a number of specific actions that States should take in order to ensure effective respect for, and promotion of the rights of peoples with autism. In this respect, the following passages could be mentioned by way of example: 'States should provide a legal framework, which ensures the right of children and young people with autism to receive education - within general schemes wherever possible - that is appropriate to their needs, is non-discriminatory and works towards social inclusion. There is a need to ensure that resources are sufficient for the full implementation of relevant legislation'; 'Following diagnosis, education for children and young people with autism should be based on detailed assessments that identify the needs and strengths of each individual. Steps should be taken to ensure that services dealing with young children are aware of these problems as early as possible'; 'Research should be carried out in support of the educational, therapeutic and inclusion strategies, because reliable information helps to identify new problems which must be addressed, to develop solutions and to obtain satisfactory results'.

In addition to the above mentioned European soft law instruments, concerning specifically the protection of persons with autism, it is important to recall the European Action Plans or Strategies concerning disability in general.

In this regard, it is worth recalling both the 'European Disability Strategy 2010-2020: A renewed Commitment to a Barrier-Free Europe', which is a Communication of the European Commission to the other political institutions of the EU (adopted on November 2010), and the 'Council of Europe Action Plan to promote the rights and full participation of people with disabilities in society: improving the

\footnotetext{
${ }^{6}$ See Sect. 4.
} 
quality of life of people with disability in Europe 2006-2015', which is a Recommendation of the Committee of Ministers of the Council of Europe adopted on April 2006. Such instruments cover of course all the situations and categories of disabilities, including autism; and they propose to national authorities significant actions to be taken also in the fields of education, vocational training, and employment, aimed in particular at: promoting inclusive education and lifelong learning for pupils and students with disabilities; enabling people with disabilities to earn their living on the open labour market; and eradicating discrimination on grounds of disability in Europe.

\section{The Rights of Persons with Autism Before the Court of Justice of the European Union and the European Court of Human Rights}

The current picture of the European legal rules and soft law instruments which are directly relevant for the protection and promotion of the rights of people with ASD is not very rich or satisfying, indeed. The existing European 'legislation' concerning expressly autism is clearly poor and not developed enough.

However, it is important to see what such rules and instruments imply and require in terms both of State legal obligations and of rights to be invoked by individuals or groups before European judges or monitoring bodies.

In this regard, it is worth considering the jurisprudence and views of the European bodies and courts which have been established to monitor and assess respect for, and implementation of, the above mentioned — few - rules by European States.

Starting from the judicial organs and institutions of the European Union, unfortunately there is not so much to say about their role in the protection of the rights of persons with autism. As mentioned above, in the framework of the EU law the main rule to which refer for the protection of people with autism (or other kind of disabilities) is Article 26 of the Charter of Fundamental Rights. But we still do not have any case law or jurisprudence of the Court of Justice on Article 26. This is presumably due, on the one hand, to the fact that the Charter entered into force, as a legally binding instrument, only 5 years ago; but it also due, on the other hand, to the inherent limited scope of application of the Charter.

In fact, the Charter does not establish any new power or task for the Union: it has to be respected by the institutions and bodies of the European Union only when applying already existing EU law and rules, and is legally binding for Member States only when they are implementing Union law or acts (Article 51 of the Charter). As a consequence, there are not many situations in which Article 26 of the Charter can be fruitfully invoked by individuals or groups to obtain respect for, or promotion to the rights of people with autism (or other kind of disabilities). 
A meaningful example of this state of affairs is the recent case of a petition lodged to the European Parliament on September 2013 by the 'Diamant Association', alleging that the right of persons with autism to education without discrimination and on the basis of equal opportunity is not respected in France, and asking the European Parliament to take steps to ensure that persons with autism in France are not treated in psychiatric clinics but integrated into specialized schools. The European Parliament requested information on this issue from the Commission. The Commission replied that 'The competencies of the Union are limited to contributing to the development of quality education by encouraging cooperation between Member States and supporting and supplementing their actions. ... Only where Member States are implementing Union law can the Commission assess whether a national law or measure is compliant with the United Nations Conventions on the Rights of Persons with Disabilities. [...] On this basis ..., it does not seem that the issues the Petitioner raises are related to the implementation of European Union law. For this reason, the European Commission is not in a position to follow up on them. It is for Member States, including their judicial authorities, to ensure that fundamental rights are effectively respected and protected in accordance with their national legislation and international human rights obligations'.

And the final answer of the Parliament to the Petition was that 'The situation raised by the petitioner does not fall within the scope of existing EU law'.

A part from the Charter of Fundamental Rights, there are of course other norms and acts of the European Union which could be usefully referred to, interpreted and applied in order to properly ensure the rights of persons with autism, taking into account their peculiar situation. A good example is the 'Employment Equality Directive' (Directive 2000/78/EC), which prohibits discrimination on the ground of disability in the field of employment, occupation and vocational training. The way in which this Directive has been interpreted and applied by the European Court of Justice in some landmark rulings can clearly have a positive impact also on national legislations and practices concerning the employment and vocational training of people with autism. ${ }^{7}$ From this perspective, are worth mentioning the HK Denmark judgment of 11 April 2013 with regard to the notion of disability and the categories of persons which are covered by the Directive, and to the meaning of 'reasonable accommodation' as including not only material but also organizational measures; and also the judgment of 4 July 2013 in the case Commission v. Italy, still with regard to the meaning of 'reasonable accommodation' and the obligation for all employers to take concrete measures allowing persons with disabilities to have effective access to employment, to participate and advance in employment, and to be trained.

Moving from the European Union to the Council of Europe, let us starting with European Court of Human Rights. To tell the truth, to date no direct contribution of the Court to the protection of persons with autism can be found or mentioned. There are of course some judgments concerning persons with disabilities which can be

\footnotetext{
${ }^{7}$ See the chapter by M. Fasciglione, in this volume.
} 
relevant also in the specific perspective of the protection of people with autism. This is the case, for example, for two old decisions concerning the right to education of disabled children, where the Court condemned the compulsory placement of children with disabilities in special nursing homes against parents' wishes (Graeme v. UK, Commission's decision of 5 February 1990, and Persson v. Swefen, of 2 July 1993). And this is also the case for a number of judgments where the Court conducted a review of the measures taken by the authorities with respect to the specific circumstances and needs of the prisoners with disabilities or with chronic illnesses. ${ }^{8}$ These cases point to the fact that disabled prisoners were disadvantaged in comparison to their non-disabled inmates and the appropriate steps were not taken to remove that disadvantage which caused them suffering and distress beyond that associated with detention. In other words, the failure to provide reasonable accommodation to prisoners with disabilities resulted in them being subjected to inhuman and degrading treatment.

Something new about the application of the European Convention on Human Rights to the specific situation and needs of autistic persons could maybe come in the next future from the assessment by the Court of a very recent application submitted by Mental Disability Advocacy Center (MDAC) against the Czech Republic: a case concerning a child with mental disability and the alleged violation of the right to equal access to education (Article 2 of Protocol No. 1 to the Convention) in conjunction with the right not to be discriminated against (Article 14 of the Convention). According to the applicant, the latter right would in particular include, for children with disabilities, the right to reasonable accommodation and inclusive education. It will be interesting to see what the Court will say in this regard.

\footnotetext{
${ }^{8}$ See Price v UK, Application no. 33394/96, judgment of 10 July 2001; Vincent v France, Application no. 6253/03, judgment of 24 October 2006; Mouisel v France, Application no. 67263/01, judgment of 14 November 2002; Khudobin v Russia, Application no. 59696/00, judgment of 26 October 2006; Xiros v Greece, Application no. 1033/07, judgment of 9 September 2010; Kupczak v Poland, Application no. 2627/09, judgment of 25 January 2009; Grori v Albania, Application no. 25336/04, 7 July 2009; Logvinenko v Ukraine, Application no. 13448/07, 14 October 2010; Raffray Taddei v France, 36435/07, judgment of 21 December 2010; Vasyukov v Russia, Application no. 2974/05, judgment of 5 April 2011; Vladimir Vasilyev v Russia, Application no. 28370/05, judgment of 10 January 2012; Artyunyan v Russia, Application no. 48977/09, judgment of 10 January 2012; Grzywaczewski v Poland, Application no. 18364/ 06, judgment of 31 May 2012; DG v Poland, Application no. 45705/07, judgment of 12 February 2013.
} 


\section{The Protection of People with Autism in the Framework of the Collective Complaints Procedure Before the European Committee of Social Rights}

But apart from and beyond the jurisprudence of European Court of Human Rights and its possible impact on the protection of the rights of persons with autism, much more directly relevant to the protection of such persons are, up to now, some decisions taken by the European Committee of Social Rights, in the framework of the so-called collective complaints procedure provided for by the European Social Charter. ${ }^{9}$ There are in fact two important decisions of the Committee concerning precisely the violation of the rights of persons with autism, as established by the above mentioned Article 15 of the European Social Charter.

We refer namely to Decision 13/2002 of November 2003 in the case AutismeEurope v. France, and to the more recent Decision 81/2012 of September 2013, in the case Action Européenne des Handicapés (AEH), still versus France. ${ }^{10}$

In Autisme-Europe v. France, the European Committee of Social Rights found that France failed to fulfil its educational obligations to persons with autism, mainly on the grounds that the proportion of children with autism being educated in either general or specialist schools was much lower than in the case of other children, whether or not disabled, and that there was a chronic shortage of care and support facilities for autistic adults.

This decision is indeed important, and not only because it has publicly qualified the inacceptable situation in France as being in violation of European legal rules

\footnotetext{
${ }^{9}$ The collective complaints procedure was inserted into the Social Charter system with the Additional Protocol of 9 November 1995. To date, only 15 States (out of the 43 States Parties to the European Social Charter) have accepted it. According to this procedure, four categories of organisations may lodge complaints, alleging that a State Party is in breach of the Charter: firstly, international organisations of trade unions and employers organisations; secondly, nongovernmental organisations which have consultative status within the Council of Europe and have been put on a special list; thirdly, the trade unions and employers' organisations in the country concerned; and fourthly, national non-governmental organisations (this last category is only entitled to submit complaints if the State Party concerned has expressly agreed to it; to date, only Finland has accepted this option). Complaints are examined by the ECSR, which, if the complaint is declared admissible, proceeds to decide on the merits of the case, that is whether the situation is in conformity with the Charter or not. The decision is taken on the basis of an exchange in writing of arguments between the parties. If necessary, the Committee may also decide to hold a public hearing where arguments are presented orally by the parties. Finally, the ECSR transmits its decision to the Committee of Ministers of the Council of Europe, which adopts a resolution and may invite the State concerned to take the necessary measures to bring the situation into conformity with the Charter.

${ }^{10}$ The European Committee of Social Rights has adopted important decisions also in other cases concerning the rights of persons with disability. See, namely, the decisions of collective complaints 41/2007, Mental Disability Advocacy Centre v. Bulgaria (3 June 2008), and 75/2011, Fédé ration international des droits de l'homme v. Belgium (18 March 2013).
} 
and obligations. It is important especially as it has clarified the contents and scope of the protection that States must guarantee to persons with autism.

In this respect, some statements in the decision deserve to be highlighted:

- States shall use a proper definition of autism in their legislation and official documents, and not an improper restrictive notion. According to the European Committee of Social Rights, the point of reference for the national definitions should be the one adopted by the World Health Organization.

- States shall take not merely legal action but also practical action to give full effects to the rights recognized to people with autism. This means, for example, an obligation to provide for adequate statistics with which to assess the situation of persons with autism and to rationally measures progress through time. But this mainly means the obligation for States to adopt concrete measures and modalities of funding for care and support facilities, within a reasonable time and to an extent consistent with the maximum use of available resources.

- Disability has to be considered a prohibited ground of discrimination, even if it is not expressly listed among the prohibited grounds of discrimination in the relevant provision of the European Social Charter (Article E). As a consequence, indirect discrimination on the ground of autism is also prohibited. This means that there is a violation when a State does not take steps to ensure that rights and advantages that are open to all (like education) are genuinely accessible also by and to persons with autism. ${ }^{11}$

Coming now to the Decision of September 2013 in the case Action Européenne des Handicapés (AEH) v. France, the European Committee of Social Rights found that France failed to fulfil its educational and training obligations to children and adolescents with autism on the grounds, inter alia: that France does not ensure that such children and adolescents are educated primarily in mainstreams schools; that it does not ensure that the work done in specialized institutions caring for children and adolescents with autism is predominantly educational in nature; and that the defective schooling of adolescents with autism has the consequence of not allowing their access to vocational training.

What are in this decision the most interesting statements from the point of view of clarifying contents and meaning of State obligations to adequately protect persons with autism?

- First of all, by referring itself to the definition of autism given by the WHO, the Committee reaffirms very clearly that autism is not a temporary disease but a disability. Therefore, considering the stable and permanent nature of all disabilities, assistance must be arranged by States, when necessary, for all part of the schooling and training of persons with autism.

- In so far as assistance in mainstream schools is concerned, States have to provide for a continuous service of such assistance throughout the school life of children

\footnotetext{
${ }^{11}$ For a more detailed analysis of the decision see Palmisano (2013), pp. 354-356.
} 
and adolescents with autism, in order to allow them to attend such schools. If such assistance is not adequately arranged, this does hamper school careers of autistic persons, provoking a process of driving away such persons from mainstream schools, which is contrary to the obligation to provide autistic persons with education within the framework of general schemes.

- The obligation to take the necessary measures to provide persons with autism with guidance and education, means that States have also the obligation to ensure that specialized institutions caring for autistic children or adolescents give education priority over other (medical, therapeutic or social) functions and activities, without leaving to education just a subsidiary role.

- The State obligation to adopt positive measures to provide persons with autism with guidance, education and training is not satisfied by merely elaborating and adopting adequate Action Plans, but it requires that such Plans are put into practice and implemented within a reasonable time.

- Moreover, the State obligation to implement positive measures to provide autistic persons with education cannot be satisfied by merely subsidizing travel to other States were children and adolescents with autism can be accommodated in specialized institutions functioning according to appropriate educational standards; it rather requires financing and organizational measures to implement these standards within specialized institutions active in the State territory.

- Last but not least, in the specific field of autism (and, more in general, of disability) indirect discrimination occurs also when an apparently neutral provision or practice — like public budget restrictions in social policy matters — ends up in putting the persons in question at a particular disadvantage, as they are more likely to be dependent on community care, funded through the State budget, in order to live independently and in dignity. Public budget restrictions cannot therefore be equally applied to the field of autism and disability, since this would result in a difference in treatment indirectly based on disability.

\section{By Way of Conclusion}

At the end of this brief survey on the legal protection of people with autism at the European 'supranational' level, we can just come back to what has been emphasized at the very beginning of these reflections.

It is true, in fact, that we still do not have a set of European rules or a European normative instrument specifically devoted to the protection of autistic persons. And it is also true that nothing is seriously going on in such direction: it is not realistic to expect European States or European political institutions to draft and adopt in the very next years a European convention or a hard-law act on the rights of peoples with autism.

However, this does not mean that there are no legal sources and rules, at the European level, which one can refer to in view of obtaining from States adequate consideration and respect for the specific needs and rights of autistic persons, as 
well as positive measures and actions to ensure that such persons fully and effectively enjoy their fundamental rights, like the right to education or to work and employment. In this sense, let us just refer, once again, to the CRPD, the ESC, the CFREU, to some EU Directives, and of course to the principle of non-discrimination.

With this in mind and in view of achieving some progress and improvements in the European Union-within Member States - in the field of protection of autistic persons, what would be needed is not so much a new European 'legislation' or a normative instrument dealing specifically with autism. Much more important than this would be, in our view, if the already-existing European rules and principles were properly applied by States, in all their implications and practical requirements.

As the experience of the European Committee of Social Rights in applying Article 15 of the ESC shows well, what is really important is to push State institutions and authorities to put into practice their existing obligations with regard to the protection of autistic persons, and to carefully monitor actions or omissions of States in this field, by rigorously assessing and emphasizing when they, contrary to their obligations, do not do anything, or do not enough to ensuring to persons with autism the exercise of their rights and participation in the life of the community.

In this respect, the advocacy action carried out by civil society associations or by European NGOs-like Autism-Europe-is extremely important, as it allows European monitoring bodies or courts to deal with concrete cases concerning the application by States of the legal rules which require them to ensuring autistic persons the effective exercise of their rights. Also research projects and comparative studies on the possible measures and best practices to give full effect to the rights of persons with autism are very useful, as they do provide competent European monitoring bodies and courts with the proper guidance to assess whether or not States and public authorities are acting in conformity with their obligations towards people with autism.

Open Access This chapter is distributed under the terms of the Creative Commons Attribution Noncommercial License, which permits any noncommercial use, distribution, and reproduction in any medium, provided the original author(s) and source are credited.

\section{References}

Arnardóttir OM, Quinn G (eds) (2009) The UN Convention on the rights of persons with disabilities: European and Scandinavian perspectives. Martinus Nijhoff Publisher, Leiden/ Boston

Marchisio S, Cera R, Della Fina V (eds) (2010) La Convenzione delle Nazioni Unite sui diritti delle persone con disabilità. Commentario. Aracne, Roma

O'Brien C (2014) Article 26. In: Peers S, Hervey T, Kenner J, Ward A (eds) The EU Charter of fundamental rights - a commentary. Hart Publishing, Oxford/Portland, pp 709-748

Palmisano G (2013) I diritti delle persone con disabilità nel Sistema della Carta sociale europea. In: Colapietro C, Salvia A (eds) Assistenza, inclusione sociale e diritti delle persone con disabilità. Editoriale Scientifica, Napoli, pp 337-361 
Schulze M (2010) Understanding the UN Convention on the rights of persons with disabilities: a handbook on the human rights of persons with disabilities. http:/www.hiproweb.org/uploads/ tx_hidrtdocs/HICRPDManual2010.pdf. Accessed 21 Nov 2014

Director of the ISGI-CNR, Full Professor in International Law (University of Camerino) and President of the European Committee of Social Rights (Council of Europe). 